\title{
Information and communication technology in science learning as a tool for "scientific thinking" in engineering education
}

\author{
Eugeny Smirnov*, Vitali Bogun \\ Yaroslavl State Pedagogical University, Yaroslavl, Russia; 'Corresponding Author: e.smirnov@yspu.yar.ru
}

Received 25 August 2010; revised 28 September 2010; accepted 3 October 2010.

\begin{abstract}
New methodologies in science (also mathematics) learning process and scientific thinking in the classroom activity of engineer students with ICT (information and communication technology, including also graphic calculator) are presented: visual modelling with ICT, action research with graphic calculator, insight in classroom, communications and reflection of integrative actions. How can we show our students the beauty of science (and mathematics) with ICT and the way scientists think and try to find the truth? Is it possible to create the motivation in science learning for students using ICT or graphic calculator? How can we organize the engineer training on such professional activity in classroom? In this paper we try to answer the questions using methodology of visual modelling and technology of resource lessons in high engineering school.
\end{abstract}

Keywords: Visual Modelling;

ICT or Graphic Calculator; Resource Lessons;

Engineer Education;

Motivation in Science (Mathematics) Learning

\section{PREAMBLE}

In education process for future engineer in science (including mathematics) we remark the lot of opportunities for developing of "scientific thinking" and special engineering skills using information and communication technologies (ICT). Using of the ICT gives rise to new opportunities in increase of motivation and efficiency of problem-solving in science as well as personal and mathematical training of the future engineer [1-4].

One of perspective directions of computerization in a science and mathematical training of engineer is using of computer-aided mathematical systems (CMS) and graphic calculators in scientific research of students in learning of science and mathematics. CMS are universal mathematical packages of symbolical and numerical calculations (MathCad, Mathematica, Maple, Derive and so on) and have joined the category of working instruments for analytical calculations. Using of a graphic calculator in teaching of science and mathematics, being an operative instrument for solving complex computing problems as well as an instrument for recording and visualization of various stages in solving of problems, raises interest to science and mathematics, makes the spectrum of cogitative operations. On the other hand, the future engineer should not treat the ICT only as the object of study of their functions, modes, options, communications in order to solve scientific and didactic problems, but as a tool to control cognitive and communication activity of students in their future professional work as well.

The opportunity of communications as well as using of information ideas in the process of exchange of didactic and scientific experience by students via Internet for distance training and use of electronic working environments as well as training material is of great importance of students more intense and influences the ways of the training contents presentation.

However, there is still some work to do. The experience of the projects mentioned show that most science teachers emphasize in their lessons the content of science; pupils must learn concepts, formulas, laws and models without ICT or some. Education in favour of acquiring declarative knowledge. Yet there are a number of contradictions connected with the ICT use in scientific training and mathematical education of the future engineer, namely:

- Between the rate of development of information technologies and the state of teaching of science and mathematics in engineering universities and colleges;

- Between opportunities of use the CMS in teaching of science and mathematics and inadequacy of 
scientific-methodical development;

- Between the necessity of creating in students the skill of construction of algorithmic model, while solving a science, mathematical and real problem, and significant volume of the calculations interfering with comprehension of a model structure;

- Between the necessity of formation computing skills of students and practical use by students of computer mathematical systems when they solve problems independently.

We understand that scientific thinking of students will be have a background if the essence of scientific recognition is opened and will be have the special educational activity of students in the integration ICT in science oriented on competence based education [5-7]. We should pay attention for scientific activity, scientific interactions and cognitive acts similar the scientists work. The good experience in technologies, the materials and infrastructure developed was considered as important for the development of patterns for repeating. We should create the innovative forms (didactical models and technologies) of organization of student activity using ICT in science with high motivation. Therefore we should consider with students the useful, beautiful and essential professional tasks in science learning using modelling and visualization of complex procedures.

In this paper we will emphasize three aspects related to science learning with ICT and the professional development of engineer in integration process. First, we think it is a good idea to emphasize the scientific methodology with ICT $[8,9]$. How can we show our students the beauty and use of science and the way a scientist thinks and tries to find the truth? Content, subject matter, will be important, but we should reach the essence of phenomena or process sometimes only using ICT. However, to introduce science for public understanding we must emphasize the thinking process of scientists. It will help the students to get a better understanding of what science and practice is all about and at the same time it will motivate them to learn (more) about science with visualization of algorithmic procedures and adequate mathematical actions. Second, we like to modelling the real phenomena and process (including mathematical, science and information models) in integration on different levels with forming the research habits and skills (with the use of ICT). At last we would like to form the engineering skills: problem solving in choice situation; operating the evaluation, creating of models of real phenomena and process on the base of visualization and using ICT.

\section{GOALS}

The problem of the research: define conditions of the
ICT integration into the process of becoming proficient in scientific and didactic problems of science and mathematical learning on the visual modeling basis of objects and processes by engineer students.

The purpose of the research: create an integral system (contents, forms, methods and conditions) of research by prospective engineer in solution of scientific and didactic problems of science education involving of the ICT and utilizing visual modeling of basis and processes.

Application of the CMS for solution of scientific and mathematical problems by students will promote growth of motivation in scientific research as well as in professsional development of the future engineer on condition that:

- The practice of visual modeling is included into educational activity during integration of science and information knowledge;

- Students construct models while solving scientific and mathematical problems with application of the CMS, which record mathematical optimum procedure mathematical and information actions;

- Students manifest creative activity while learning to use the CMS (a variation of data and analysis of results, formation of hypotheses and their testing, inter-conversion of the sign systems);

- Communicative opportunities for groups dialogue of students during their educational activity is enlarged by means of information environments (Media, Internet, conferences and so on).

Tasks: (scientific, didactic, information, methodologycal, professional):

- Study functional possibilities and analyze the basic CMS and Graphic calculator, create the models for modes of work in the information environment;

- Reveal didactic conditions and develop a technique of visual modeling using the CMS (the graphic calculator) during teaching of science and mathematics and solving of scientific problems;

- Develop a laboratory workshop aimed at solving of science and mathematical problems using the CMS (the graphic calculator) and the methods of its conducting for students on resource lessons;

- Design interactive volume of information by groups of students on the basis of authoring software products and the results of the CMS (graphic calculator) research;

- Visualize the procedure of science and information actions on the basis of improvement of students' computing and logic culture.

\section{SCIENTIFIC METHODOLOGY}

The results and products of psychology theories and conceptions will be input for a paper where we will em- 
phasize the creative way in which the acquirement of scientific knowledge takes place. They are: competence base education, visual modelling, scientific thinking, integration levels and motivation process. We will answer the question how to introduce the ICT in process of scientific thinking and professional skills forming into the learning process of students in engineering education. Action research with ICT will be introduced as a tool for future engineer to improve their profession.

\subsection{Visual Modeling of Objects and Procedures with ICT}

The pedagogical technology of visual-modeling learning of science and mathematics plays a fundamental role in the proposed didactic system of science and informatics integration of knowledge and actions [10,11]. This technology makes it possible to achieve stochastically guaranteed result of teaching of various qualitative levels of learned material as well as integrity of representation of the basic science, information and mathematical structures.

According to our concept use of visual methods in learning or teaching of science of a future engineer is treated as a special property of psychological images of science or mathematical objects, the essence of which is considered in an integral paradigm of perception of the basis of the following criterions:

1) Diagnosable aim-finding of integrity of the science or mathematical object;

2) Adequate perception (learner's comprehension of essence of the science or mathematical object in accordance with aims of learning or teaching);

3) Stability of perceptive image and presentation under conditions of direct perception;

4) Cognitive and creating activity on the basis of relaxed and successful learning.

\subsection{Aims and Indicators for Success}

To reach goals related to our goals as formulated in the preceding paragraph we must:

In relation with the scientific methodology:

- Analyse the (international) experiences on how to attract future engineer to science with ICT;

- Investigate whether and how the ideas of students on science and the scientific world change during the project;

- Describe learning activities (also including ICT) in relation with "creative and scientific thinking" (paradigm shift);

- Design activities that can take place within the regular curriculum and/or during short time thematic projects;
- Pilot the develop lesson modules as resource lessons with ICT in engineering education in Russia.

In relation with action research:

- Introduce the methodology of action research with ICT;

- Support future engineer during the process of action research with ICT;

- Create and analyse the methodology of resource lessons with ICT and rewrite the modules.

- Develop a manual to show future engineer how to implement and use action research with ICT in their professional practice

- Develop a manual to show future engineer how to implement the kind of activities we designed during the project.

- Create the base of professional oriented tasks with using ICT in different levels and forms.

It is required to teach students to project and investigate mathematical models utilizing the ICT in such components where their application is necessary and justified (complex computing algorithms, visualization and recording of various stages of science, mathematical or information actions, construction of complex graphic objects, etc.) [2]. Thus construction of integrative information model, which optimizes use of an information resource (functions, commands, modes, algorithms, etc.) is a very important problem (Figure 1).

Developing the genesis of learning element with ICT as pedagogical problem (object for mastering by another subject in learning process with ICT) require the calculation not only mental experience, person characteristic and conditions of activity, but system analysis of analogical substructure of future subject of mastering in new pedagogical conditions.

\subsection{Diagnostic Procedure for Defining of Students Motivation and Calculation of Positive Shifts}

Cognitive interest determines the activization of:

1) Achievement motives:

- Presence of adequate result in practical activities;

- Construction of mathematical and science model of process or the phenomenon;

- Ability to consolidation (in thinking of the pupil and activity) the initial data for the decision of a problem;

- Realization of a choice in methods and procedures of tasks decision;

- Appearance of pupils insight in action research;

2) Social motives are defined by the dialogue and interaction in small group:

- A choice of a social role; 


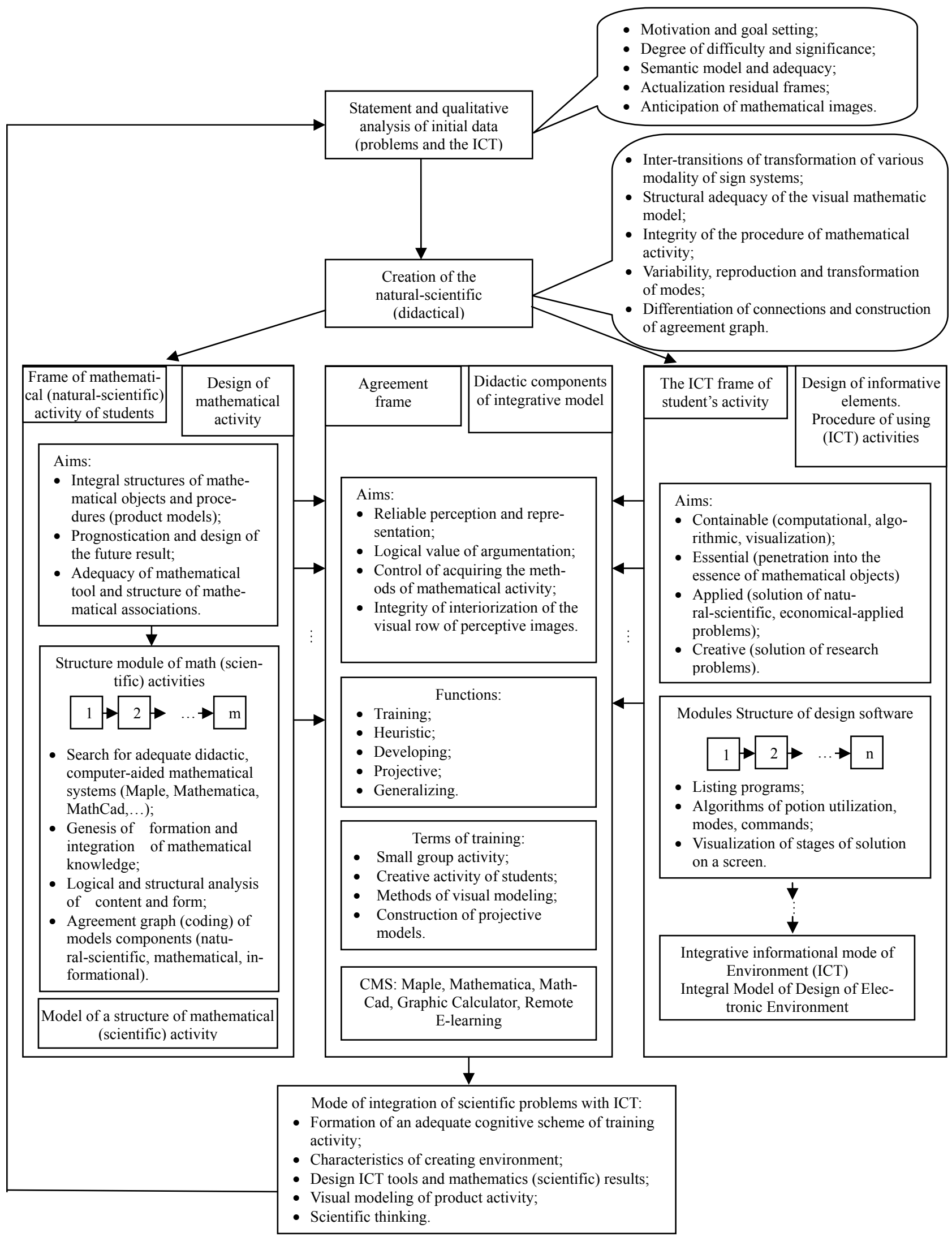

Figure 1. Integrative model of mathematics (science) and ICT activities. 
- Social tests and search positive (internal and external) results of dialogue;

- Expansion and development of activity in a direction of self-realization of the person;

3) Motives in action research of pupils:

- Actualization of pupils insight;

- Integration of thinking efforts of pupil;

- Visual modeling in knowledge and process

We try to use methodological ideas of problem solving, visual modeling, work in small groups, humanizing of science and mathematics education with ICT:

- Setting of the productive science problem with mathematics and informatics decision (actualizetion of science, informatics and mathematics knowledge of the last years on the basis of integration; participation in discussion and statement of educational tasks; construction of science, informatics and mathematical model of process or the phenomenon; ability to consolidation (in thinking of the pupil and activity) the initial data for the decision of the problem);

- Educational activity of pupils on high level of complexity (quasi-research activity of pupils aimed at analysis of results and search of new patterns of relationships; search experiment using numerical methods and computing procedures, diagnostics of information dynamics of parameters; monitoring and correctional interaction of obtained results, search of integrative knowledge and prospect of development; skills of visual modeling and estimation of real processes);

- Efficiency of using resources (material, materialized, ideal) for activization of cognitive processes and social interaction (presence of adequate results in practical activities; joint analysis, information interchange, presentation of results; visual modeling in educational activity; reflection and internal plan of pupils action);

- The organization of work in small groups (distribution and the choice of social roles, planning, fore- casting, acceptance of decisions, selection of the data and modeling, registration of results; social tests and search positive (internal and external) results of dialogue; expansion and development of activity in the direction of self-realization of the person).

As the result of such approach on organization of learning process for students in engineering universities we introduce the notion of "resource lesson with ICT" as the form of teachers and students activity for two subjects in one lesson on the ICT-base, so we define the "resource" as a necessary volume of the educational in- formation in science (mathematics) sufficient for successful development of pupils' proficiency of in mathematics (science) according to educational aims, integration of subjects on the ICT-base and following characteristics:

- Equal volume and complexity of subjects material (science, informatics and mathematics knowledge);

- Setting of subjects aims (scientific, informatics and mathematical);

- Setting of science and real problem with using of ICT and mathematical resource (algorithms, countable, logical, sign-symbolical, modeling and so on);

- Computing and science experiment;

- Social activity of pupils and work in small groups;

- Preliminary procedure of actualization of science, informatics and mathematics knowledge;

- Teachers manage the learning process of students together.

To our minds, one way to deal with the specified problems is to realize technology of visual modeling and conduct "resource lessons" at which the interrelation of learning material on science, informatics and mathematics is revealed to its full and individual activity of pupils grows.

\section{GOOD PRACTICE USING ICT (GRAPHIC CALCULATOR, MAPLE) ON "RESOURCE LESSON"}

The analysis of curriculum on physics and mathematics has shown the mismatch of sections learning and has defined the "resource lesson" and "coordination graph" technologies constructions. We look on two lessons in Russian schools concern with "resource lesson" methodology. Testing applying to more than 1000 pupils of secondary schools has shown strong influence the volume of mathematics in science on pupils motivation. At the same time it will be grown the level of "scientific thinking" and research activity of pupils.

First one is the title "Fall of the body" for 10 class of secondary school (integration of ICT, physics and mathematics) using the graphic calculator.

\subsection{Purposes and Problems}

- Using Newton Second Law to research of the real physical processes (the building physical, informatics and mathematical models, structures acting power, procedures and mathematical dependencies);

- Use the numerical methods for the decision of the 
physical problem with ICT-graphic calculator (the method iteration, approximations, derived to differential relations);

- Use the graphic calculator for complex current calculations and visualizations stages of decision of the physical problem ;

- Substantial interaction of informative and physical resources (visual modeling, structure, levels, dynamics, forms, efficiency) using mathematical tools;

- Motivation to physics learning using informatics and mathematics for personal development of pupils.

\subsection{Setting of the Problem}

The body by the mass $70 \mathrm{~kg}$ falls with the big height. The power of the air resistance is finding by the equation $\mathrm{F}_{\mathrm{re}}=\mathrm{Av}+\mathrm{Bv}^{3}$, where factors $\mathrm{A}$ and $\mathrm{B}$ are defined of the body size. Let these factors are the following values: $\mathrm{A}=$ $5 \mathrm{H} \cdot \mathrm{s} / \mathrm{m}$ and $\mathrm{B}=10^{-2} \mathrm{H} \cdot \mathrm{s}^{3} / \mathrm{m}^{3}$. We must to find the velocity depending on time, passed after begin falls. Trace the

graphics $v(t)$ and $s(t)$.

\subsection{Organization Work in Small Groups}

\subsubsection{Features}

1) Dialogue, discussions and criticism in behavior and thinking of pupils;

2) The analysis, information interchange, presentation of physical and mathematical results;

3) Integration of graphic calculator using and estimated and algorithmically activity of pupils.

\subsubsection{Procedure}

Work in small groups with the purpose of self-determination, self-realization and activization of independent cognitive and creative activity of pupils (groups on 5-6 pupils are united on personal sympathies and interests with possible rotation of structure and distribution of functions and roles in group):

\subsection{Mathematical Model}

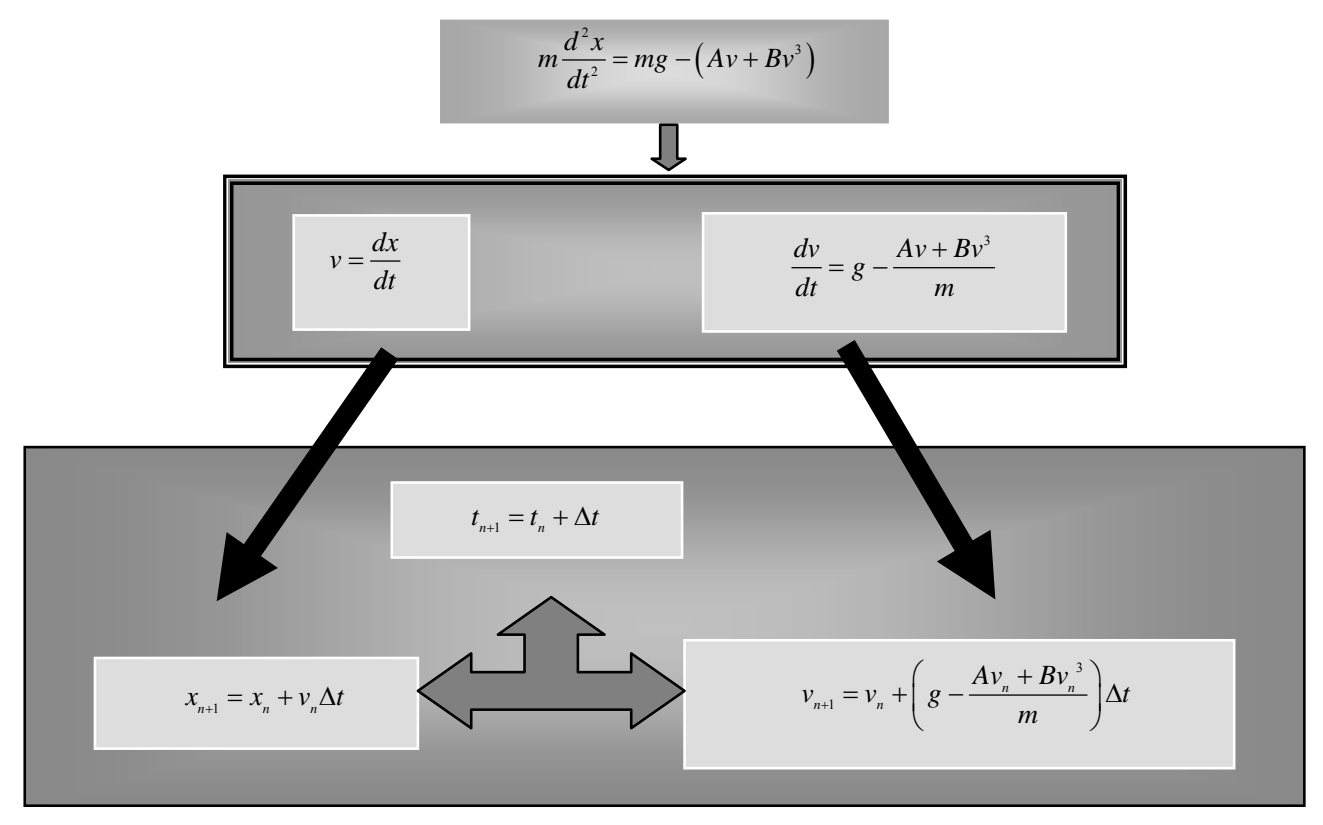

We should use in this procedure the method of sequential approximation for calculation the values of $v(t)$ and $s(t)$ as functions from time. The students can change the values of $A, B, m, t$ for view (by using the graphic calculator opportunities) on dynamics of process. They can answer on questions:

Is a function $v(t)$ monotone?

Can you find the time of body landing?

What happened with time landing, velocity landing if the body will have the different initial velocity?

How can you see that happened with velocity and time landing if the mass will be different?

The students can fill the table of values, view the graphics, to find the analytical decision of the problem.

\subsection{Activity of Pupils}

- Distribution of social roles in small group, an individualization of educational activity (planning, forecasting, acceptance of decisions, selection of the data and modeling, managing of graphic calculator using, registration of results; 


\begin{tabular}{|c|c|c|}
\hline GROUP 1 & GROUP 2 & GROUP 3 \\
\hline $\begin{array}{l}\text { INPUT M? } \\
70 \\
\text { INPUT A? } \\
5 \\
\text { INPUT B? } \\
0.01\end{array}$ & $\begin{array}{l}\text { INPUT G? } \\
9.81 \\
\text { INPUT N? } \\
10 \\
\text { INPUT DELT? } \\
0.1\end{array}$ & $\begin{array}{l}\text { INPUT T0? } \\
0 \\
\text { INPUT V0? } \\
0 \\
\text { INPUT X0? } \\
0\end{array}$ \\
\hline
\end{tabular}

- Presentation of research results in small groups and reflection

\section{CONCLUSIONS AND SUGGESTIONS}

The analysis of these results made us feel confident that the hypothesis concerning the opportunity to increase motivation in learning of science (mathematics) by incorporating into science (mathematics) lessons of suitable mathematics (science) material is consistent and logical. It can be achieved by means of development of "resource lessons" and activization of cognitive activity of engineering students by visual modeling and group work activity. The conducted research has shown the importance of the chosen topic and has partially confirmed the put forward hypothesis about the significance of the integrated approach to interaction of science and mathematics with ICT in engineering education. Research of the innovative approach in visual modeling of science, informatics and mathematical processes, activetion of motivational and cognitive processes have promoted positive changes in personal development and successful mastering (learning) of teaching material. Resource lessons with ICT as basic form of realization of interaction of science, informatics and mathematics has shown its efficiency and opportunity for further research. It is recommended to develop the cycles of resource lessons with ICT in learning of science and mathematics at University and to carry out a detailed analysis and feasibility of the technological innovations.

On the basis of the model and the method of research we have worked out ideas on the series of "resource lessons" with ICT for engineering students (also using computer mathematical system: Maple, MathCad, Mathematica and so on) on the laboratory work on science or lessons in mathematics.

Together with teachers and teacher educators we have to design more lessons, to carry out those lessons in classrooms and to analyze the lessons and the knowledge of the students. We also want to design lesson activities in which engineering students can learn by means of computers as a learning tool more scientific problems. The experiences are very promising and we like to investigate the use of simulations and computer based laboratory work in relation with "resource lessons" in mathematics and science.

\section{REFERENCES}

[1] Savenkov, A.I. (2006) Psychological foundation of research approaches in education. MISE, Moscow.

[2] Bogun, V.V. and Smirnov, E.I. (2008) Using of graphic calculator in teaching mathematics. Yaroslavl State Pedagogical University, Yaroslavl.

[3] Bustraan, W. and Smirnov, E.I. (2003) MISE, motivation in science education (international project Russia, Austria, Holland). Herzen State Pedagogical University, St. Petersburg.

[4] Voogt, J., Gorokhovatsky, J. and Almekinders, M. (2003) Information and communication technology in rural schools: Innovative didactics in physics teaching. University of Twente, Enschede.

[5] Arnold, V.I. (2000) Soft and strong mathematical models. Nauka, Moscow.

[6] Smirnov, E.I. (1998) Technology of teaching mathematics using visual modeling. Yaroslavl State Pedagogical University, Yaroslavl.

[7] Salmina, N.S. (1988) A sign and a symbol in teaching. Publishing House of the Moscow State University, Moscow.

[8] Smirnov, E.I., Bogun, V.V. and Ostashkov, V.N. (2007) Visual modeling in mathematics: Theory and practice. Indigo, Yaroslavl.

[9] Smirnov, E.I., Shadrikov, V.D., Povarenkov, Y.P. and Afanasyev, V.V. (2002) Teacher training of mathematics: Innovative approaches. Gardariki, Moscow.

[10] Shadrikov, V.D. (1996) Psychology of activity and abilities of the person. Logos, Moscow.

[11] Mrotchek, V. and Philippovitch, F. (1910) Pedagogic of mathematics. V.1., St. Petersburg. 